University of Nebraska - Lincoln

DigitalCommons@University of Nebraska - Lincoln

Faculty Publications from the Department of Electrical \& Computer Engineering, Department Electrical and Computer Engineering

5-6-1983

\title{
Interfacial Electrical Properties of Ion-Beam Sputter Deposited Amorphous Carbon on Silicon
}

\author{
A. Azim Khan \\ University of Nebraska-Lincoln \\ John A. Woollam \\ University of Nebraska-Lincoln, jwoollam1@unl.edu \\ Y. Chung \\ Universal Energy Systems, Dayton, $\mathrm{OH}$ \\ B. Banks \\ NASA Lewis Research Center, Cleveland, $\mathrm{OH}$
}

Follow this and additional works at: https://digitalcommons.unl.edu/electricalengineeringfacpub

Part of the Electrical and Computer Engineering Commons

Khan, A. Azim; Woollam, John A.; Chung, Y.; and Banks, B., "Interfacial Electrical Properties of lon-Beam Sputter Deposited Amorphous Carbon on Silicon" (1983). Faculty Publications from the Department of Electrical and Computer Engineering. 1.

https://digitalcommons.unl.edu/electricalengineeringfacpub/1

This Article is brought to you for free and open access by the Electrical \& Computer Engineering, Department of at DigitalCommons@University of Nebraska - Lincoln. It has been accepted for inclusion in Faculty Publications from the Department of Electrical and Computer Engineering by an authorized administrator of DigitalCommons@University of Nebraska - Lincoln. 


\title{
Interfacial Electrical Properties of Ion-Beam Sputter Deposited Amorphous Carbon on Silicon
}

\author{
A. AZIM KHAN, STUDENT MEMBER, J. A. WOOLLAM, SENIOR MEMBer, Y. CHUNG AND B. BANKS
}

\begin{abstract}
Amorphous, "diamond-like" Carbon films have been deposited on Si substrates, using ion-beam sputtering. The interfacial properties are studied using capacitance and conductance measurements. Data are analyzed using existing theories for interfacial electrical properties. The density of electronic states at the interface, along with corresponding time constants are determined, and the density of interface states is unusually low for an as yet unoptimized
\end{abstract}

\section{INTRODUCTION}

A MORPHOUS, "DIAMOND-LIKE" Carbon films have been studied at least since 1971, when Aisenberg and Chabot reported on the successful deposition of such films using an ionbeam technique [1]. Since then amorphous Carbon films, which are hard and semi-transparent (thus the "diamond-like" description), have been deposited using a number of other techniques. Among these are cracking of hydrocarbons in a glow discharge (both de and RF) [2]-[4], ion-beam sputtering from a Carbon target [5], etc. It is no surprise, then, that the physico-chemical properties of such films comprise a wide range. In general, these Carbon films produced by any technique are characterized by their smooth and hard surface, high electrical resistivity, optical transparency (visible and/or $I R$, depending on the method of preparation), excellent resistance to corrosive chemicals, high dielectric strength, contollable refractive index, good adhesion to diverse substrate materials, and low thermal expansion. These properties are highly desirable in a number of application, e.g., protective coatings on optical components, AR coatings for solar cells, laser windows in the IR regime, etc. [6]. Most of the available literature therefore deals with the investigation of various deposition techniques and the physico-chemical properties of the resulting deposits.

In their first paper dealing with diamond-like Carbon films (also called i-Carbon), Aisenberg and Chabot [1] reported on the ability of these films to form a barrier against sodium ion migration using a bias-temperature (BT) stress test. They also calculated the interface state density using flatband voltage shifts of the capacitance. To our knowledge no

Manuscript received January 3, 1983; revised March 2, 1983. This work was supported by the NASA Lewis Research Center under Grant NAG-3-95, and the University of Nebraska Research Council.

A. A. Khan and J. A. Woollam are with the Department of Electrical Engineering, University of Nebraska, Lincoln, NE 68588.

Y. Chung is with Universal Energy Systems, Dayton, OH 45432.

B. Banks is with the NASA Lewis Research Center, Cleveland, OH 44135 . serious efforts to study interfacial properties of i-Carbon films on $\mathrm{Si}$ or any other substrate have been made to date. In this letter, we report on what we believe to be the first results on the electronic properties of the Al/C/Si MIS structure.

\section{EXPERIMENTAL}

Wafers of 3-in-diameter P-Si with (111) orientation were used as substrates. Amorphous, "diamond-like". Carbon films were deposited at the NASA Lewis Research Center by ionbeam sputtering from a Carbon target [7]. Wafers were loaded into the diffusion-pumped $\left(10^{-6} \mathrm{~mm}\right)$ deposition chamber and cleaned in situ for $60 \mathrm{~s}$ with an ion-beam etch. From previous experiments, the $\mathrm{SiO}_{2}$ etch rates were known to be $\cong 80 \AA$ per minute, and the oxide thickness was known to be $\cong 30 \AA$. Thus the oxide was removed and some etch of the silicon surface took place. Some heating of the surface was evident during etching but the temperature was not measured. Thus slight self-annealing could have taken place during etching. There was no deliberate voltage biasing or heating of the substrate. During deposition the beam current was $55 \mathrm{~mA}$ at $1 \mathrm{KV}$ with a beam diameter of $10 \mathrm{cms}$. The resulting films were pale yellow, shiny smooth, and hard with excellent adhesion to the substrate. These wafers were then diced in to 12 by $12-\mathrm{mm}$ pieces for further processing. Some samples were used for Raman, IR absorption, and ellipsometric studies. The physico-chemical properties of the films inferred from these experiments will be described in a future communication [8]. Aluminum dots were evaporated on other samples using a clean ion-pumped vacuum system. Capacitance and conductance measurements were taken on these samples. The frequency range of $100 \mathrm{~Hz}$ to $10 \mathrm{MHz}$ was used in all experiments. Measurements below $1 \mathrm{KHz}$ were, however, not very successful due to noise problems. Thickness and refractive index were found using ellipsometry.

\section{Theory of Conductance Measurements [9]}

The normalized equivalent parallel conductance of a single level interface state characterized by the time constant $\tau$ can be written as

$$
\frac{G_{p}}{\omega C_{I}}=\frac{q D_{i t} \omega \tau}{\left(1+\omega^{2} \tau^{2}\right) C_{I}}
$$

It is highly unlikely, however, than an insulator-Si interface will introduce a single level in the Si bandgap. It is more likely 
TABLE I

\begin{tabular}{cccc}
\hline Wavelength & $n$ & $k$ & Thickness \\
$6328 \AA$ & 2.07 & -.0 .087 & $1376 \AA$ \\
$5640 \AA$ & 2.05 & -0.130 & $1376 \AA$ \\
$3650 \AA$ & 2.07 & -0.346 & $1376 \AA$ \\
\hline
\end{tabular}

that the induced levels will appear as a continuum distributed over the entire bandgap. In this case one gets

$$
\frac{G_{p}}{\omega C_{I}}=\frac{q D_{i t}}{2 \omega \tau C_{I}} \ln \left(1+\omega^{2} \tau^{2}\right) .
$$

From (1), the maximum value of $G_{p} / \omega C_{I}$ occurs at $\omega \tau=1$, while from (2) it occurs at $\omega \tau=1.98$. These conditions are used to directly extract interface state time constants from the measured data. In the specific case of the $\mathrm{Si}-\mathrm{SiO}_{2}$ interface, it is well known that the interface states not only form a continuum, but that the time constant dispersion is much greater than is expected on the basis of a simple continuum $((2))$ of states. This enhancement is due to random fluctuations of the Si surface potential in the plane of the interface.

\section{RESULTS}

The initial estimates of the thickness and refractive index made by a Rudolph Research automatic ellipsometer at $6328 \AA$ were found to be $900 \AA$ and 2.69 , respectively. These crude numbers were used as initial estimates in a detailed multiple angle of incidence ellipsometric study to be reported elsewhere [8]. Table I lists results of these measurements on one sample. ( $n$ is the index of refraction, $k$ the extinction coefficient.)

The breakdown field is estimated to be $\sim 5 \times 10^{5} \mathrm{~V} / \mathrm{cm}$ and resistivity around $10^{9} \Omega \cdot \mathrm{cm}$.

A typical $C-V$ plot taken at $10 \mathrm{KHz}$ is shown in Fig. 1. In general, $C-V$ plots are characterized by negligible hysteresis, sharp transition (from depletion to accumulation), and small flat-band voltage shifts. There is, however, considerable frequency dispersion in accumulation. A frequency versus maximum capacitance plot is shown in Fig. 2 to illustrate frequency dispersion of capacitance. The density of interface states was determined by curve fitting to (1) and (2). The density of states versus gate bias is shown in Fig. 3. Unfortunately, we cannot precisely relate gate voltage to $\mathrm{Si}$ surface potential in these early samples due to charge leakage, which makes it difficult to obtain reasonable quasistatic $C-V$ characteristics. Hence, the graph should be taken as a qualitative feature of results from this $(\mathrm{Al} / \mathrm{C} / \mathrm{Si})$ system. The charge leakage, however, was not enough to cause any problem in other measurements reported here. The most interesting result of this study is shown in Figs. 4 and 5. These figures indicate that over the entire range of gate bias investigated, the $G_{p} / \omega C_{I}$ versus $\log f$ data show good fit to theory only if either a) a single time constant or b) a continuum of states is assumed. The curve fitting in these cases is done as follows. The maximum value of $G_{p} / \omega C_{I}$ is obtained experimentally at each fixed bias, and the frequency corresponding to this maximum is recorded. These values are

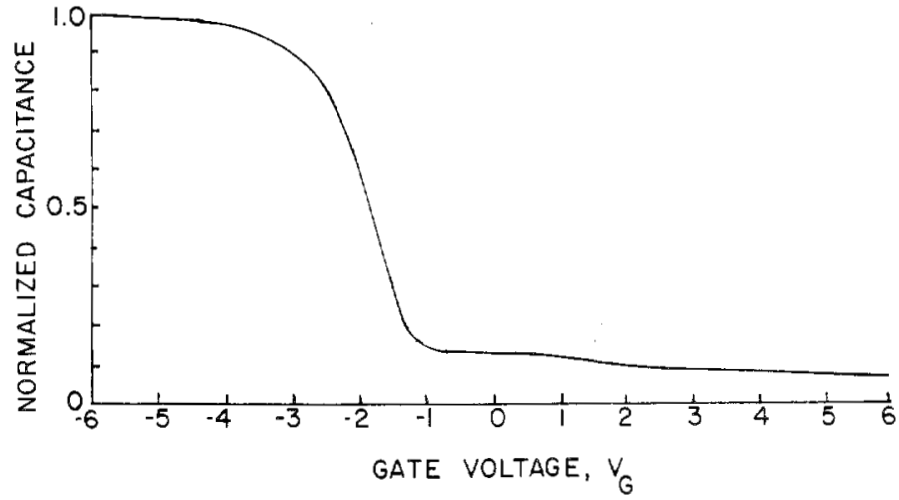

Fig. 1. $C-V$ characteristics of Al/i-C/Si MTS structure at $10 \mathrm{kHz}$.

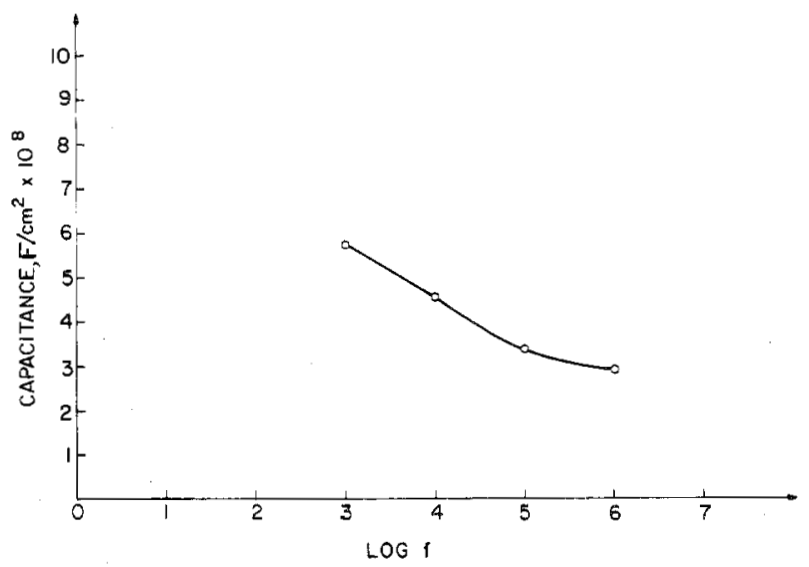

Fig. 2. Frequency dispersion of capacitance in strong accumulation.

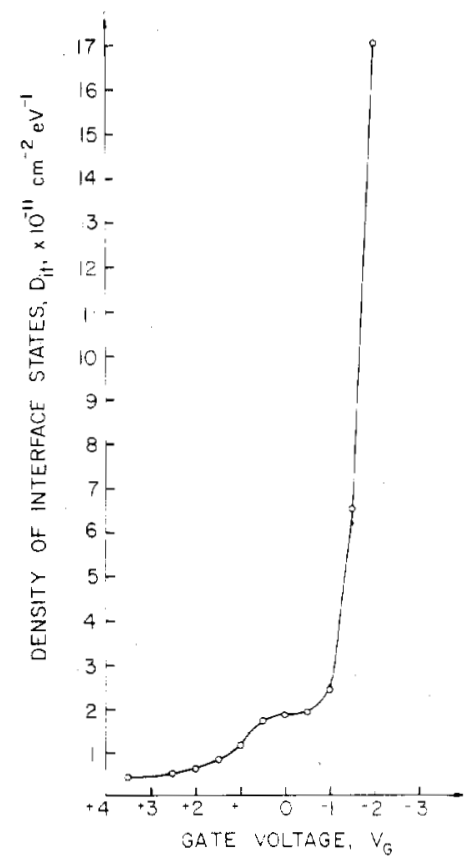

Fig. 3. Density of interface states $D_{i t}$ as a function of gate voltage. 


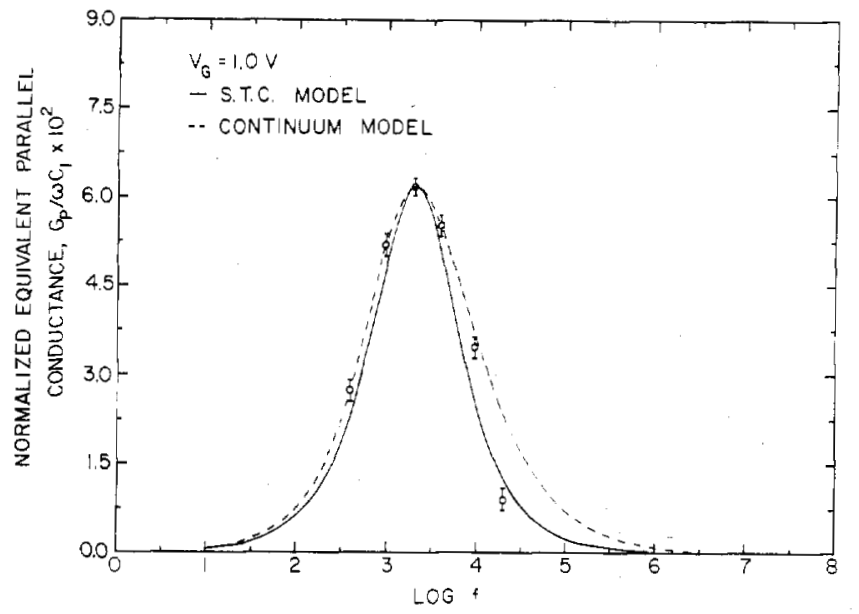

Fig. 4. Normalized equivalent parallel conductance versus log frequency at a gate voltage of $1.0 \mathrm{~V}$.

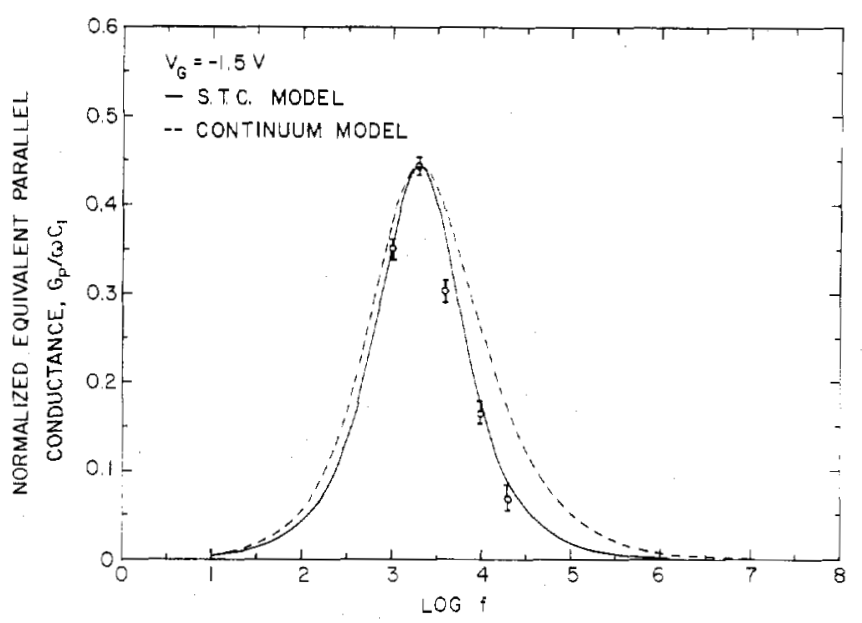

Fig. 5. Normalized equivalent parallel conductance versus log frequency at a gate voltage of $-1.5 \mathrm{~V}$.

then substituted into (1) to evaluate $D_{i t}$ based on a single time constant model and into (2) to evaluate $D_{i t}$ based on a con. tinuum model. These values are then substituted again into (1) and (2), respectively, to generate theoretical $G_{p} / \omega C_{I}$ versus $\log f$ plots. It is clear that the experimental data fall on predic. tions of these two models only. This is surprising in view of the fact that the $\mathrm{SiO}_{2}-\mathrm{Si}$ interface exhibits a large time constant dispersion in the depletion region. A single time constant behavior is observed only in the weak inversion region, where it is due to the presence of minority carriers. We have observed the same type (single time constant/continuum) behavior at all other values of the gate bias in the range $-3.5 \mathrm{~V} \leqslant V_{G} \leqslant 3.5$ $\mathrm{V}$, although the fit is not quite as good.

Finally, interface state time constants evaluated from these measurements (using conditions on $\omega \tau$ mentioned above) are plotted as a function of gate bias in Fig. 6. Notice that some of the points are scattered around the straight line. This is due to the fact that the measuring instruments HP4274A and HP42$75 \mathrm{~A}$ measure conductance only at a few discrete values of the frequency. Hence, the exact value at which the conductance peaks at a given value of the gate bias cannot be located with

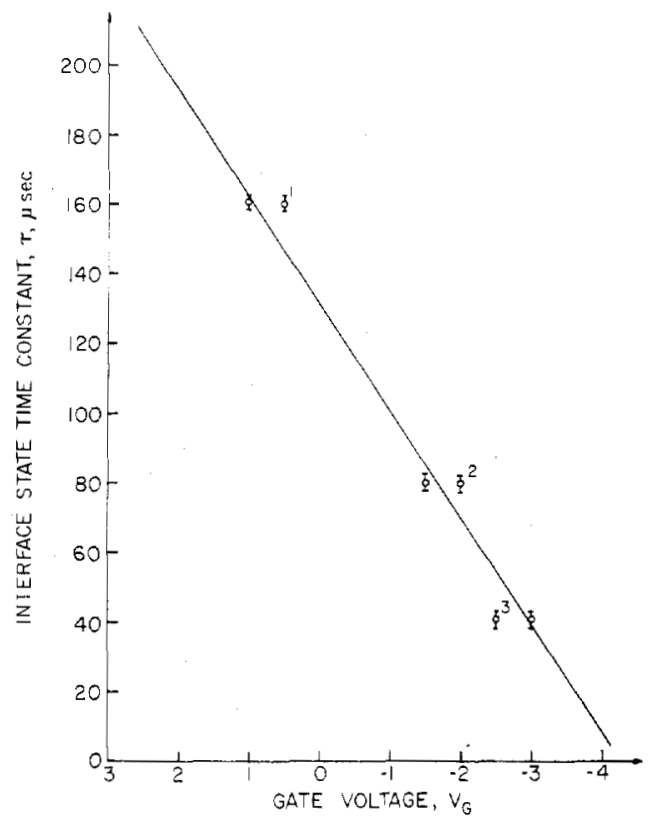

Fig. 6. Interface state time constant $\tau$ versus gate voltage. Note the scatter of points due to the inability to sweep the frequency continuously, e.g., points marked 1, 2, and 3 will fall on the line if the peak value of $G_{p} / \omega C_{I}$ is assumed to occur at $2.1,2.2$, and $2.9 \mathrm{kHz}$ at these values of the bias.

certainty. This also explains the systematic displacements of measured data from the theoretical $G_{p} / \omega C_{I}$ versus $\log f$ curves (not shown) at these bias values.

\section{SUMMARY AND CONCLUSIONS}

We have studied the electrical propertties of the i-Carbon/Si interface. We find it very interesting that this interface does not exhibit the large dispersion of interface state time constants commonly associated with the $\mathrm{SiO}_{2} / \mathrm{Si}$ interface [9]. Similar behavior (the lack of time constant dispersion) has, however, been reported in other MIS structures [10], [11]. The frequency dispersion in accumulation is disturbing, but its magnitude is much less than is commonly observed in most other MIS structures (except metal/ $/ \mathrm{SiO}_{2} / \mathrm{Si}$ ) [12] - [14]. It is usually attributed to the classical Maxwell-Wagner effect [15], i.e., to the formation of a highly resistive layer at the interface. In our case, such a layer could have been formed as a result of the surface damage during in situ cleaning, although these problems make it doubtful if the conventional equivalent circuit [16] is truly applicable. It is possible that other loss mechanisms (besides interface states, such as tunnelling into insulator states) may also be contributing to the data presented. It is important to notice, however, that the total ac loss is so small that a first-order (continuum of states) calculation yields $D_{i t}$ values, which are reasonably low from a device point of view. Since we have only used a few samples so far, the $D_{i t}$ can possibly be reduced further by optimization of surface preparation and annealing procedures. Experiments are underway to improve reproducibility, reduce charge leakage problems, and study annealing behavior of these films. We are also investigating dc sputter deposited a-C films on Si. Preliminary results are encouraging. 


\section{ACKNOWLEDGMENT}

We wish to express our thanks to the staff of Avionics Laboratory of the Wright-Aeronautical Laboratories, WPAFB, Dayton, OH. In particular we wish to thank Dr. P. Stover and Dr. D. Langer for their hospitality during the one-month residence at WPAFB of A.A.K. during the summer of 1982 . We thank P. Shinyeda and the Motorola Corporation of Phoenix, AZ, for supplying the silic on substrates.

\section{REFERENCES}

[1]. S. Aisenberg and R. Chabot, "Ion beam deposition of thin films of diamondlike carbon," J. Appl. Phys., vol. 42, no. 7, p. 2953, June 1971.

[2] D. S. Whitmell and R. Williamson, "The deposition of hard surface layers by hydrocarbon cracking in a glow discharge," Thin Solid Films, vol. 35 , p. $255,1976$.

[3] L. Holland and S. M. Ojha, "Deposition of hard and insulating Carbonaceous films on an r.f. target in a butane plasma," Thin Solid Films, vol. 38, p. L17, 1976.

[4] S. Berg and L. P. Anderson, "Diamond-like Carbon films produced in a butane plasma," Thin Solid Films, vol. 58, p. 117, 1979.

[5] C. Weissmental, in Proc. 7th Int. Vacuum Congr, and in Proc. 3rd Conf. Solid Surfaces, (Berger, Vienna), 1978, p. 1538.
[6] Workshop in Diamond-like Carbon Films, April 19-20, 1982, EDM Corp., Albuquerque, New Mexico.

[7] B. A. Banks and S. K. Rutledge, "Ion beam sputter deposited diamondlike films," NASA TM82873, 1982.

[8] D. Mathine, A. A. Khan, R. O. Dillon, and J. A. Woollam, "Optical properties of diamond-like carbon films-An ellipsometric and spectroscopic study," to be published.

[9] E. H. Nicollian and J. R. Brews, MOS (Metal Oxide Semiconductor) Physics and Technology. New York: Wiley, 1982, p. 207

[10] J. C. Kim, "InSb MIS structures for infrared imaging devices," in IEDM, (Washington, D.C.), Dec. 1973

[11] J. D. Langan and C. R. Viswanathan "Characterization of improved InSb interfaces," J. Vac. Sci. Technol., vol. 16, p. 1474, 1979.

[12] A. Heime and H. Pagnia, "Influence of the semiconductor-oxide interlayer on the AC-behavior of InSb MOS-capacitors," J. Appl. Phys., vol. 15, p. 79, 1978

[13] L. G. Meiners, "Capacitance-voltage and surface photovoltage measurements of pyrolytically deposited $\mathrm{SiO}_{2}$ in InP, Thin Solid Films, vol. 56, p. 201, 1979.

[14] T. Sawada and $H$. Hasegawa, 'Small signal admittance study of GaAs anodic MOS system," Phys. Stat. Sol., vol. (a) 54, p. 689, 1979.

[15] R. A. Van Hipple, Dielectrics and Waves. New York: Wiley, 1954, p. 412

[16] S. M. Sze, Physics of Semiconductor Devices. New York: WileyInterscience, 1969, p. 446. 